\title{
Identifying the Public's Psychological Concerns in Response to COVID-19 Risk Messages in Singapore
}

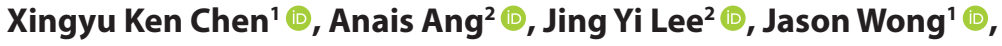 \\ Neo Loo Seng' ${ }^{1}$ (D), Gabriel Ong ${ }^{2}$ (D), and Majeed Khader ${ }^{2}$ (i) \\ 1. Nanyang Technological University, Singapore \\ 2. Home Team Behavioural Sciences Centre, Ministry of Home Affairs
}

\begin{abstract}
Understanding the social-psychological processes that characterize communities' reactions to a pandemic is the first step toward formulating risk communications that can lead to better health outcomes. This study examines comments on Facebook pages of five Singapore media outlets to understand what topics are being discussed by the public in reaction to the implemented precautionary measures in Singapore so as to infer their psychological concerns. Using Anchored Correlation Explanation as a topic modelling technique, this study examines around 10,000 comments and identifies 21 topics that are discussed. The 21 topics were categorized and organized into seven broad themes of psychological concerns. Implications for theory and practice are then discussed.
\end{abstract}

KEYWORDS: COVID-19, public reactions, HBM, collectivism, risk perception, topic modelling

The COVID-19 pandemic has introduced a multitude of risks into people's lives, both physical and psychological in nature (Ho et al., 2020). Many countries around the world implemented measures such as national lockdowns, quarantines, closure of workplaces and schools, and border restrictions to slow the spread of the COVID-19 virus.

CONTACT Xingyu Ken Chen (D) • E-mail: xychen1991@gmail.com • Nanyang Technological University • 50 Nanyang Ave • 639798, Singapore

Copyright 2021 Authors. Published under a Creative Commons Attribution 4.0 International (CC BY-NC-ND 4.0) license. 


\section{A Brief Background to Singapore's Response to the Pandemic}

On January 23, 2020, Singapore announced its first imported case of the COVID-19 virus (Abdullah \& Salamat, 2020). A nationwide partial lockdown, which is known as the Circuit Breaker, was imposed on April 7, 2020, to curb the rapid rise of COVID-19 community and dormitory cases in Singapore (Ministry of Health, 2020), which had grown to over 200 cases at the time. For example, during the Circuit Breaker, non-essential workplaces had to be closed and adopt telecommuting (Ministry of Health, 2020). Dine-ins at food establishments were not allowed, except for takeaways and deliveries (Abu Baker, 2020).

The measures worked, and the number of new cases had dropped significantly after August 2020 (Nurhayati-Wolff, 2021), and commentators credited it to the community's role in complying with the measures announced by the government to combat the pandemic (Turrell, 2021). Singapore also had the lowest death rate in the world, which has been attributed to a combination of detection measures, an adaptable healthcare system, and a culture that was quick to adopt mask-wearing and other protective measures (Aravindan, 2020).

In terms of health risk communications, the local authorities used multiple channels of communication such as Facebook, Twitter, Telegram, and WhatsApp to provide frequent and timely updates about what people should do during such times as well as to inform them about the various restriction measures (e.g., mask-wearing, limitations in group-gatherings) that were implemented (Gov.sg, 2020; Leong, 2020). The government also leveraged local media outlets to spread the messages about precautionary measures that need to be taken (Koh, 2020).

\section{Understanding Public Concerns on Social Media}

The ability of individuals to carry out the recommended actions (e.g., practicing physical distancing) is critical in limiting the spread of the disease outbreak. Identifying the concerns that people can have toward government precautionary measures during a pandemic can have practical and conceptual significance for disease control. Furthermore, understanding the social-psychological 
processes that characterize communities' reactions to a pandemic is the first step toward formulating risk communications that can lead to better health outcomes.

Examining social media posts is important as social media has been used by the public as an immediate source of information not just during the COVID-19 pandemic but also disease outbreaks in the past (Jang \& Baek, 2019). In the context of a health epidemic, there is a strong influence of an individual's sources of information on their behaviour. For instance, researchers found that changes in media attention mirrored changes in the willingness of individuals to adopt precautionary actions during the $2009 \mathrm{H}_{1} \mathrm{~N}_{1}$ pandemic (Ibuka et al., 2010). During the COVID-19 pandemic, more Singaporeans turned to traditional news media and social media for swift and important crisis-related information (Rekhi, 2020). Chua (2020) found that while news of the outbreak has been featured in the local news since late 2019, a considerable spike in reactions on Facebook occurred when Singapore's first case was announced. Comments found on such platforms can provide clues for understanding what the public's concerns are and what should be done to address them.

Hence, the current study analyzed Facebook comments toward the Singapore government's precautionary measures, which were collected from the pages of five Singapore media outlets. Approximately 10,000 comments collected from the Facebook pages of five Singaporean media outlets from January 2020 to June 2020 were analyzed to identify common concerns that surfaced. Consequently, identifying the concerns that led to the formation of pandemic-related health beliefs as well as the cultural factors behind the public's reactions can widen the existing evidence base for existing health communication theories and policymaking.

\section{Health Belief Model in Pandemic Response}

According to the Health Belief Model (HBM), perceptions such as the perceived susceptibility to the disease or perceived selfefficacy are relevant in influencing the public's beliefs toward the precautionary measures they should take during a health crisis. HBM posits that health-seeking actions are influenced 
by individuals' perceptions of the health risk and efficacy of the behaviours intended to address the threat (Rosenstock et al., 1988). In the current COVID-19 pandemic context, the HBM has been used as a framework for guiding effective risk communications to the public (Carico et al., 2020), educational interventions (Elgzar et al., 2020), recommendations for developing contact-tracing apps (Walrave et al., 2020), and understanding public perception about the virus (Jose et al., 2020).

According to HBM, the constructs proposed to predict health-seeking behaviour are: perceived threat (comprised of perceived susceptibility and perceived severity), perceived benefits, perceived barriers, and perceived self-efficacy. When assessing whether to act or not (i.e., complying with precautionary measures proposed by the government), the public is likely to need information related to the components in the HBM to inform their risk judgments - the likelihood of contracting COVID-19, the severity of contracting COVID-19, how effective the precautions are, and assurance that they would be able to carry out the proposed precautions.

HMB has been widely used in other public health campaigns as it can identify the main barriers to people's intention to adopt a health behavior-often informing policies that create better health outcomes across various contexts such as increased physical activity, reduced smoking, and improved adherence to prescribed medications (Ng et al., 2012; Ryan et al., 2008). According to the HBM, people are more likely to perform health-seeking actions to address the threat when they perceive a health risk and have the self-efficacy to perform these actions.

Health risk communications that addressed the concerns that people have can affect an individual's interpretations of the risk as well as their willingness and ability to act timely (Ryan et al., 2008; Vaughan \& Tinker, 2009). These psychological concerns can range across various psychological needs such as autonomy over one's decisions, feelings of being trusted and understood, and feeling able to manage the situation (Porat et al., 2020). 


\section{The Role of Collectivism in Pandemic Response}

Cultural factors also play a role in pandemic response. During a pandemic, there are likely to be trade-offs between the collective and individuals in response to the threat. Members of more individualistic cultures, such as the United States, are socialized to value independence, autonomy, and being distinct from others. On the other hand, those in more collectivistic societies, such as Singapore and China, view the self as interdependent with other members, emphasize group cohesiveness, and give priority to group goals over individual goals (Triandis, 2001).

Cultural factors may impact individuals' attention and perceived importance of stressors when assessing the threat, which in turn influences their psychological needs and behavioural response (Guan et al., 2020). Unsurprisingly, there have been multiple studies examining the influence of collectivism on several aspects of the COVID-19 pandemic, including infection transmission (Jiang et al., 2020), prevention intention (Huang et al., 2020), and compliance with precautionary measures (Huynh, 2020; Kasdan \& Campbell, 2020).

Individual risk perception, psychological maladjustment, and emotional and behavioural responses during disease outbreaks have been found to differ across cultures (Germani et al., 2020). The individualism-collectivism dimension of culture, in particular, has often been used to understand the difference in responses and risk communication needs across different countries dealing with health crises (Kim et al., 2016; Willis \& Painter, 2019).

The following research questions (RQs) were developed from the review of the literature on HBM and collectivism to understand the public's concerns that were made in response to precautionary measures implemented by the government.

RQ1: What are the concerns that the Singapore public surfaced in response to the measures announced by the government?

RQ2: How does collectivism shape some of these concerns?

Hence, in order to contribute to the evidence base for risk communications during a health pandemic, the current study 
examines the public's reactions to government precautionary measures to identify their concerns from a psychological perspective. Approximately 10,000 comments collected from the Facebook pages of five Singaporean media outlets from January 2020 to June 2020 were analyzed to identify common topics discussed in these groups. The psychological concerns of the public were then inferred from these topics to help answer RQ1 and RQ2.

\section{Method}

\section{Data Collection and Cleaning}

Data from January 2020 to June 2020 was collected from the following Facebook pages of five media outlets reporting on events in Singapore: Channel News Asia, Mothership, The Straits Times, TODAY, and Yahoo Singapore. According to Statista (2020b), these media brands were the top five online sites used by Singaporeans. Furthermore, due to the heavy usage of Facebook in Singapore (Statista, 2020a), examining Facebook comments of these media brands over other social media platforms would provide a more reliable gauge of public concerns.

A set of keywords (e.g., "COVID," "social distancing," etc.) was used to obtain the relevant posts from the Facebook pages (see Figure 1). These keywords were selected by the authors based on the high face validity in extracting posts related to the topic of precautionary measures implemented by local authorities during the COVID-19 crisis. Posts with no comments were then removed to form a collection of 248 posts containing 40,686 comments. Inclusion and exclusion criteria (e.g., a post must reference a precautionary measure announced by Singapore to combat COVID-19) were used to determine if a post was relevant to the study. Then data cleaning (e.g., removing spam comments and conducting text preprocessing) was conducted. After the data cleaning was done, it reduced the number of posts to 118 , containing 10,287 comments. 


\section{Data Analysis}

Due to the volume of data and the nature of extremely short messages inherent in Facebook comments-a topic modelling technique, Anchored Correlation Explanation (Anchored CorEx) was used to analyze and identify topics that best describes the 10,287 Facebook comments. Anchored CorEx has been used in various areas of research, such as consumer purchases of vitamins (John et al., 2019), as well as to detect COVID-19 related stress symptoms (Li et al., 2020).

Anchored CorEx (Gallagher et al., 2017; Ver Steeg \& Galstyan, 2014) is a semi-supervised approach, which was used to identify the topics in the dataset. Anchored CorEx is a topic modelling algorithm that examines how words are used in the messages that are being examined, and they pick up on patterns and estimate what the documents convey with little direct supervision from the researcher. As a semi-supervised approach, Anchored CorEx also allows the user to provide the topic model with "anchor words" that represent potential topics that the model should converge upon (see Figure 1).

\section{Results}

\section{Description of the Topics Discussed on Facebook}

Twenty-one topics were generated using Anchored Corex (see Table 1). Finally, a close reading of the messages in each topic was conducted in order to identify and group the topics into the themes of psychological concerns during public discussion of COVID-19 measures in Singapore. The inferred topics were then based on the analysis of the five most representative words as well as the comments for each topic. Figure 2 shows the histograms of topics for Facebook comments. As seen in Figure 2, the top three most discussed topics (Topic 14, 13, and 1) were inferred to be about: (1) Strong public support for the mobilization of law enforcement officers; (2) many people want to know more epidemiological information about the virus; (3) debate over the safety benefits versus privacy concerns of contact tracing devices. Next, the 21 topics were subsequently categorized and manually organized into seven broad themes of psychological concerns, which are surfaced by the public. 


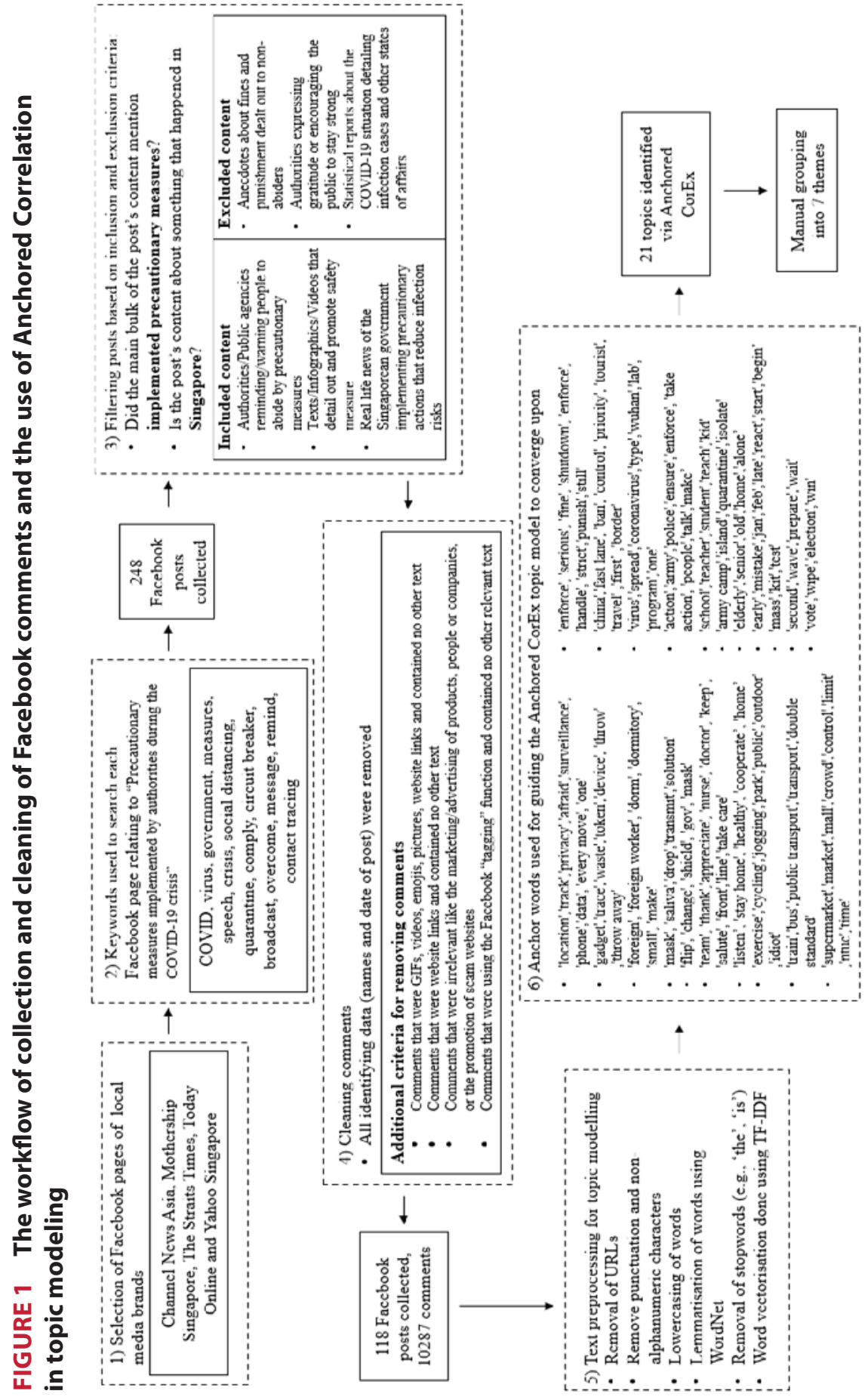




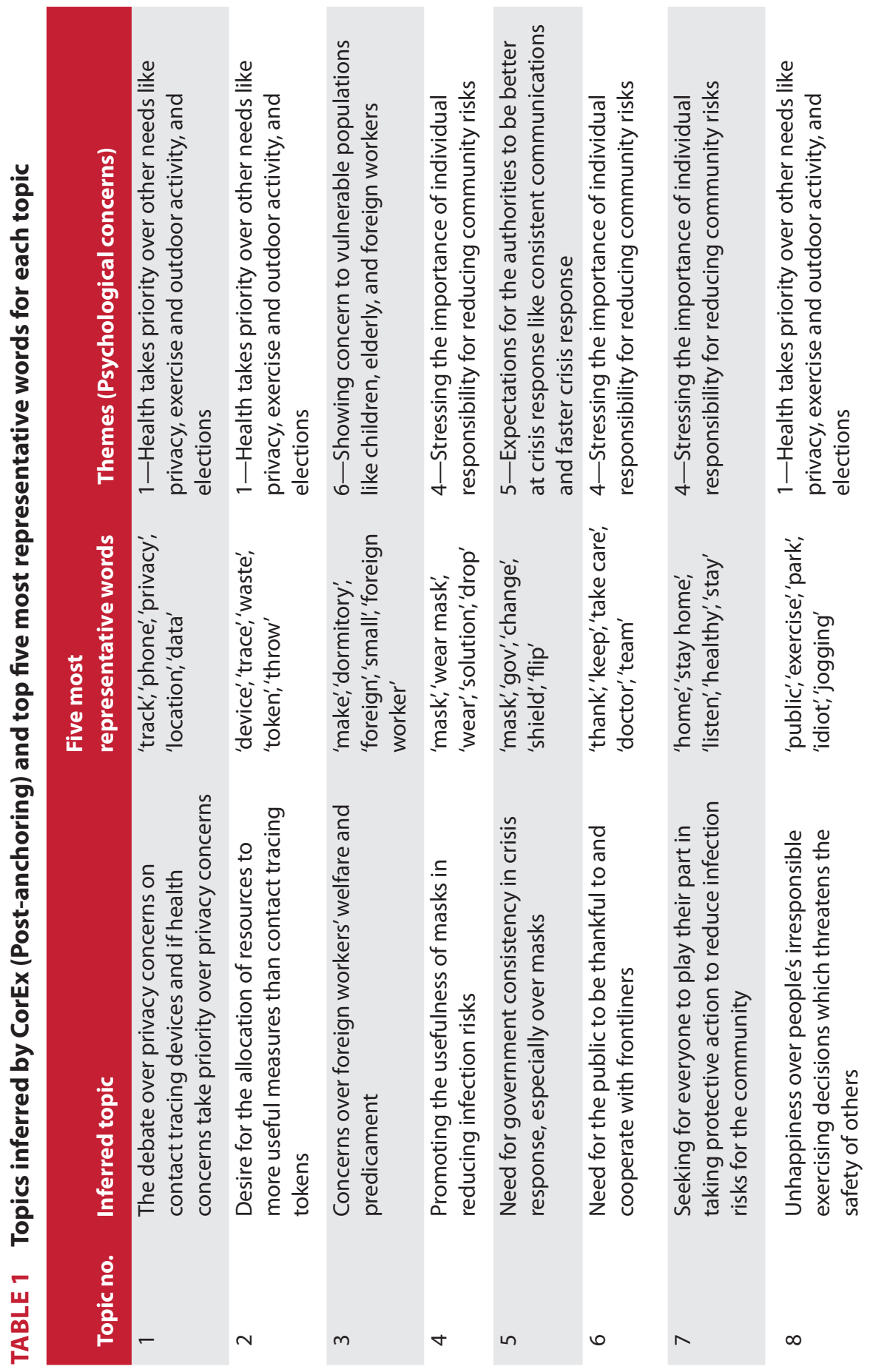




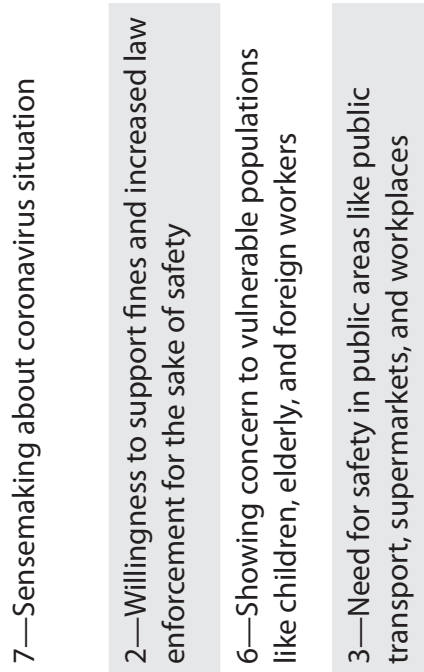

高 iv $\stackrel{c}{=}$ 言
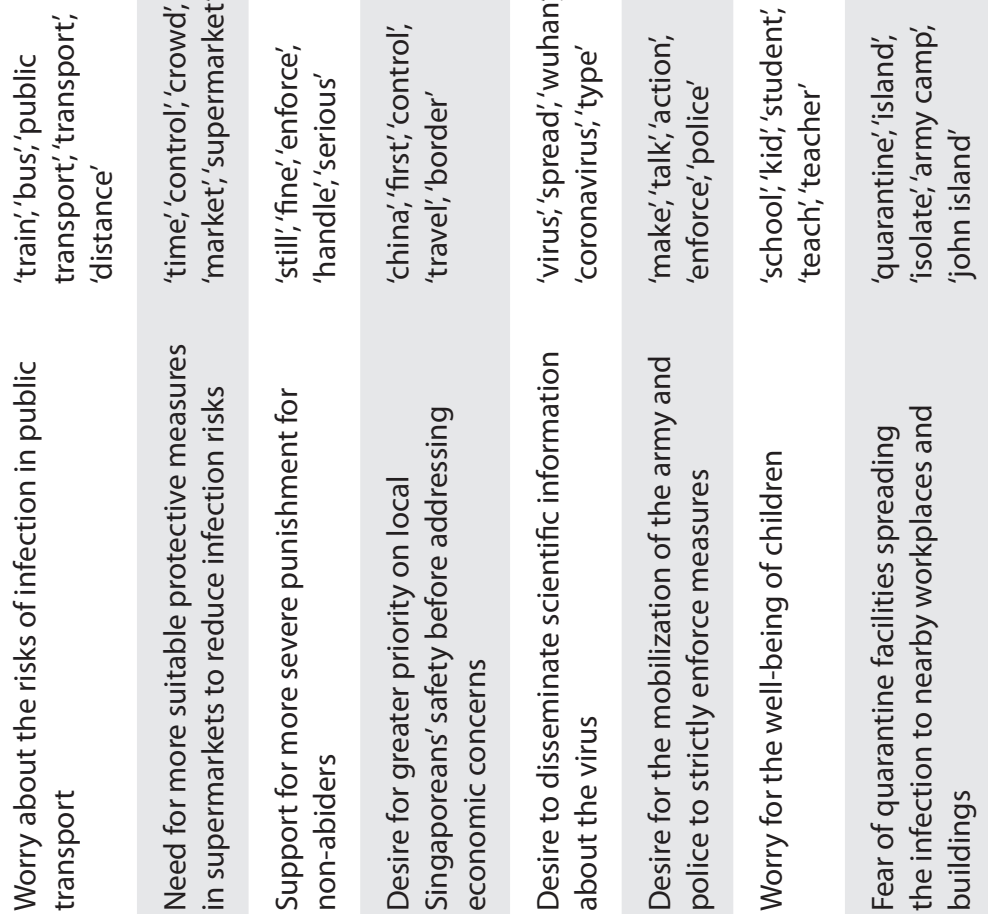

这

$a$

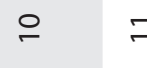

\begin{abstract}
$\stackrel{\sim}{\sim}$
\end{abstract}

m

$\stackrel{n}{\leftarrow}$ 


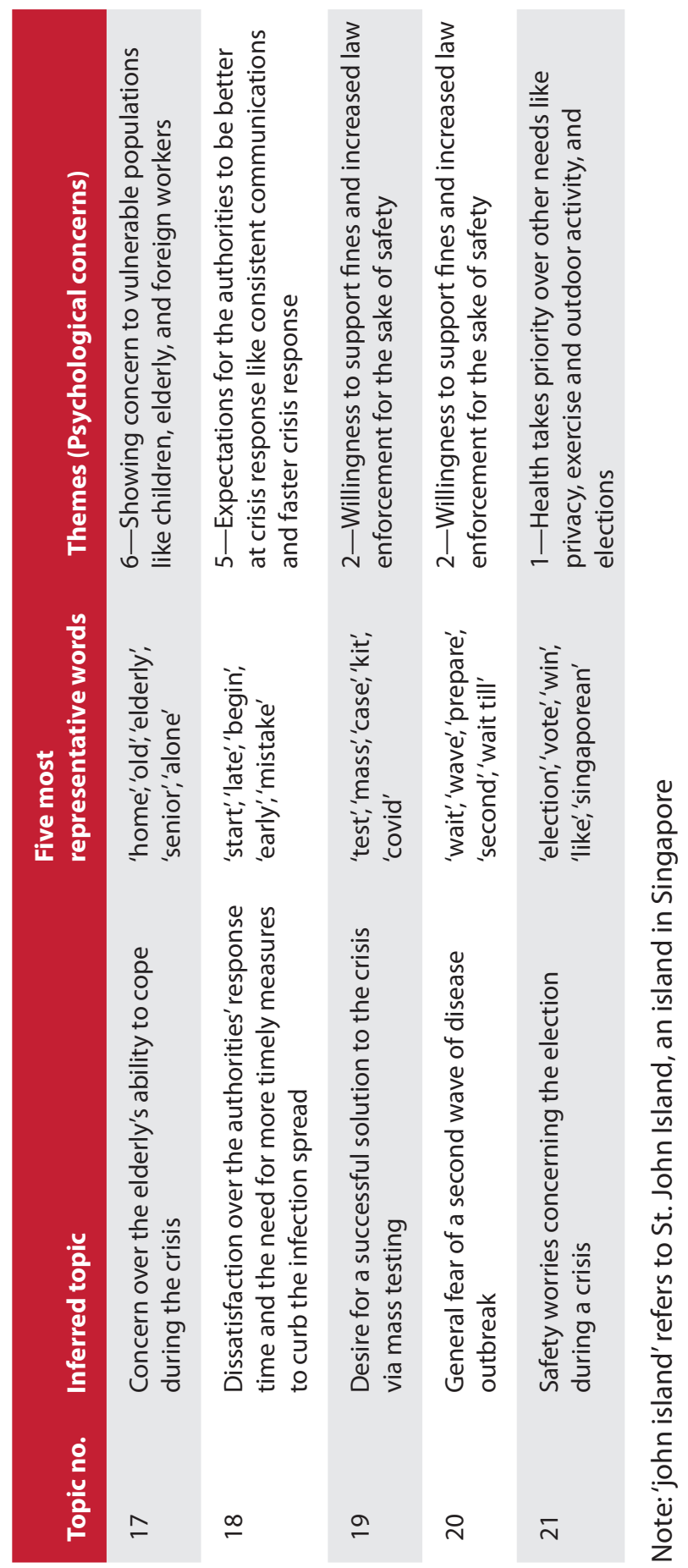


FIGURE 2 Histogram of topics in the dataset and the number of Facebook comments per topic

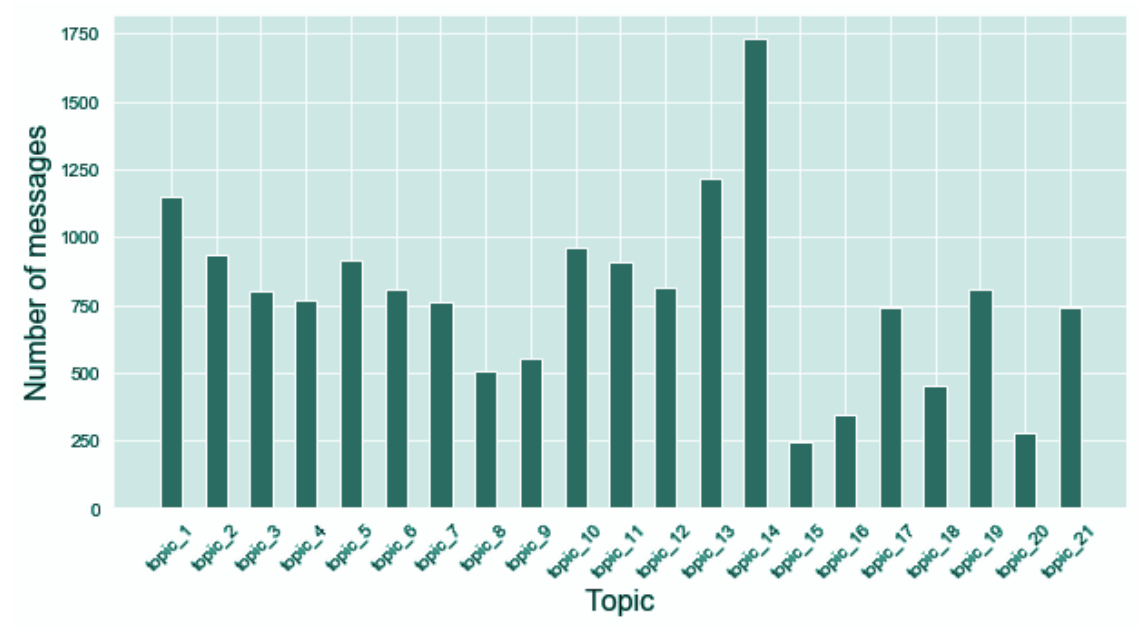

Theme 1: Protection from the Threat of the Pandemic Takes Priority over Other Concerns Like Privacy, Exercise, and Elections

This theme focused on the public's concern of focusing on protecting oneself from the health threat posed by COVID-19. For example, for some members of the public, privacy infringements (Topic 1) are considered relatively trivial, as seen in a comment like this: "Privacy is not an issue because cctv is everywhere... already tracking our movement . . . This device government-issued contact-tracing device] . . can save lives and allow our economy to stay open, why oppose? . . " However, these arguments are still contested by others, who counter that by stating that ". . do people want it to be even more invasive being tracked by local authorities ... may even come with built-in listening devices ... track all citizens' movements in the future..." Others have wondered if resources can be better spent in other more effective measures besides contact tracing tokens as seen in comments such as: "Will we end up creating more digital junk and wasting the money that could have gone to a more useful purpose?" (Topic 2). The public was also quick to express unhappiness over others who go to public spaces to exercise (Topic 8), which could increase the spread of the disease, as 
seen in the comment here: ". . people still go to East Coast Park. Lots of them . . . Just because it was stated that we could exercise ... we exploit the ruling... What does it take to drill it into our thick skull that this is a situation that our lives are at stake?"

It was also during 2020 where Singapore's general elections were held. Prior to the elections, the public was surfacing their concerns about a possible spread of COVID-19 if an election were to be held (Topic 21).-

\section{Theme 2: Willingness to Support Fines and Increased Law Enforcement for the Sake of Safety}

This theme showed that the public was willing to support fines (Topic 11; e.g., the comment here, ". . . implement fine and jail sentence for people who just won't listen to social distancing . . . the Mentality of Singaporeans and How you can make us listen-We Fear Fines.") and greater law enforcement (Topic 14; e.g., "Why keep on talking and no action? Can't you deploy the NEA, Police Force and the Active Soldiers, to enforce/make sure all Singaporean and Foreigners do their part and comply with the Circuit Breaker Measures.") to prevent a worsening of the situation, such as a second wave of infections. Some even desired the government to take strong actions (Topic 19, 20) such as implementing mass testing and preventing people who are tested positive from further spreading the disease (e.g., "Pls look into saliva test kits ... If everyone has this available in their household and make to test every day and stop them from going out to public places if they are tested positive").

\section{Theme 3: Need for Safety in Public Areas Like Public Transport and Supermarkets}

This theme focuses on the worry over potential vectors for disease outbreaks and the public's concerns about the safety of these public areas, such as public transport (Topic 9; e.g., "How to do social distancing... The most easy area virus spreading is in the enclose area like MRT and Buses. Never focus root cause"), supermarkets (Topic 10, e.g., "It's the structural concept of the supermarket-the width of the alleys are not wide... You can control the traffic outside the supermarket ... but it's not possible to control traffic of customers within the supermarket bcos there are alot of movements."). 


\section{Theme 4: Stressing the Importance of Individual Responsibility for Reducing Community Risks}

The fourth theme is about the role of an individual's actions in safeguarding the community. The importance of individual responsibility in fighting the virus for the collective good has been consistently stressed, such as wearing of masks (Topic 4; e.g., "Source or self MFG face mask is the solution... mask can prevent droplet from entering their nose and mouth. Give free mask when a person goes into a building or MRT . ..") or to self-isolate (Topic 7; e.g., "Let us just do our part and stop criticising, complaining for now ... The crucial part is we should all stay at home ... Stay safe and stay healthy."). Additionally, frontline staff were appreciated for their role in the pandemic fight, and some have urged others to help them by staying at home (Topic 6; e.g., "Thank you all the doctors, nurses $n$ those in the hospital helping to prevent the COVID19 virus and we will do our part to STAY AT HOME!")

\section{Theme 5: Expectations for the Authorities to Be Better at Crisis Response Like Consistent Communications and Faster Crisis Response}

The fifth theme illustrates dissatisfaction with the government's handling of the situation and reflects the public's expectations for the authorities to safeguard them from harm. Some have claimed that much more stringent efforts should have been done much earlier by the authorities, (Topic 18; e.g., "If $u$ and your colleagues were more determined $n$ resolute in your approach in March, waited for new developments day by day, Singapore would be in better position today. Never wait for the storm. Drastic measures like Safe Distancing $n$ Circuit Breaker could have initiated earlier in March."). Policy U-turns, especially regarding advice on masks, can create anxiety and show how the public desires consistent messaging (Topic 5; e.g., ". . . the mark of an incompetent set of leaders is flip-flopping of policies . . . First wear mask only when unwell, now wear . . . DEAR LEADERS, THINK THOROUGHLY FIRST CAN BEFORE OPENING YOUR MOUTHS CAN?"). During the pandemic, some expressed dissatisfaction with the easing of travel restrictions implemented, stating that there is no need to rush to 
open up until the situation is completely normal (Topic 12; e.g., ". . government so eager to open to China first when Singaporeans have not even gone back to normal life! . . there is no need to rush to open to them first! Stop making the citizens pay for the mistake!").

\section{Theme 6: Showing Concern to Vulnerable Populations Like Children, Elderly, and Foreign Workers}

The sixth theme reflects the concerns that the public has for vulnerable populations such as the elderly, children, and foreign workers. For the elderly, there were concerns about their ability to adopt protective actions to keep themselves safe during the crisis (Topic 17; e.g., "Please spare a thought for elderly with dementia. It is hard to keep them cooped up at home and also hard to get them to wear a mask all the time when they are taken out for a short walk. They will not understand the need for a mask and will yank out the mask."). For the children, there were concerns over infection risks in schools and preventing them from potential exposure to the virus (Topic 15; e.g., "But remember Teachers. What you are teaching are theory only... The correct thing to do now is close all schools and do e-learning. Prevent the kids from exposure."). For the foreign workers living in dormitories, there is the worry of infection risks due to communal living (Topic 3; e.g., ". . . living conditions of the dormitories too crowded, plus the poor hygiene knowledge of the workers ... dormitory management group who must implement the corrective plans and actions for the dormitories").

\section{Theme 7: Sensemaking about Coronavirus Situation}

The final theme (Topic 13) concerns how the public makes sense of the pandemic by discussing the epidemiological characteristics of the virus (e.g., "Virus have ZERO mobility. It has no legs, wings or fins. It relies on humans to transport them from host to host. If humans stop transporting them, the transmission of COVID WILL STOP") as well as discussion and rumors of the origins of the pandemic (e.g., Coronavirus may have originated in lab linked to China's biowarfare program.). 


\section{Discussion}

To address RQ1, the topic modelling approach has helped to quickly and empirically identify psychological concerns in response to the COVID-19 pandemic. As seen in Table 1, the top three most discussed topics were inferred to be about: (1) Strong public support for the mobilization of law enforcement officers; (2) many people want to know more epidemiological information about the virus; (3) debate over the safety benefits versus privacy concerns of contact tracing devices. Subsequently, the topics were grouped into seven themes. The pattern of the themes was consistent with the HBM and collectivism, which will be discussed below.

\section{Perceived Susceptibility and Public Concerns}

The findings indicate that one construct found within HBM, perceived susceptibility, can be mapped onto some of the themes. Perceived susceptibility to health risk is seen in Theme 3, reflecting the public's concern about the risks in public areas like public transport, supermarkets, and workplaces. People may feel the need for better health and safety measures taken during the COVID19 pandemic, especially in public areas where there is a perceived high likelihood of viral transmission due to high human traffic and interaction. Likewise, how other people in the public spaces comply with the precautionary measures would also influence their perceived vulnerability of contracting the virus. Taken together, it is important to provide reassurance to the public that the authorities have put in place and reinforced safety measures in the public areas and that others are complying with these measures.

Theme 7 , which is about sensemaking during a coronavirus situation, shows the public's need to gather information on the measures taken to manage the spread of the virus. As a sensemaking activity, information gathering helps them to understand the COVID-19 situation better, as well as the risk of contracting the COVID-19 virus and the actions they should take to protect themselves and others (Rosenstock et al., 1988). During the COVID19 pandemic, Singaporeans are likely to turn to mainstream news media (e.g., The Straits Times and Channel News Asia) and social 
media sites (e.g., Facebook) for swift and important crisis-related information.

\section{Collectivism in Response to a Pandemic}

Moreover, the themes were also consistent with how people in collectivistic culture respond to a crisis. Singapore is considered a collectivistic culture, and the public's values and priorities may manifest as psychological concerns during a pandemic and when the local authorities issue risk warnings. To address RQ2, themes on placing priority on safety benefits over privacy concerns and looking to authorities for more information and mobilization of precautionary measures explored how collectivism shapes some of these public concerns.

For example, in Theme 1, the protection from the pandemic threat is given more priority over other issues like privacy, exercise, and elections. This is consistent with existing research on how people in collectivistic cultures tend to prioritize the collective interests of the group (Hofstede, 2001). During a health crisis, the public will be more concerned about whether the nation can sufficiently protect its citizens from the COVID-19 threat. Hence, the public in Singapore likely expects authorities to put the nation's health at the forefront in their response to the COVID-19 pandemic, at the expense of individual interests (e.g., desire to socialize in public places, inconvenience of wearing masks, etc.).

There are also expectations for individuals to be responsible for reducing the risk of COVID-19 transmission in the community, as seen in Theme 4. These expectations are consistent with the understanding that people in collectivistic cultures are more likely to perceive their own health outcomes as dependent on the actions taken by other people, especially if those people are in their close social circle (Germani et al., 2020). They are more likely to stress the need for individuals to put collective interests at the forefront to feel that they are protected from the COVID-19 virus.

Furthermore, Theme 6 is about showing concern to vulnerable populations like children, the elderly, and foreign workers. As people in collectivistic societies tend to perceive themselves as highly interdependent and connected with others in their communities, 
during periods of heightened threat like the COVID-19 pandemic, feelings of collectivism rise, along with the need to protect other members of society. This manifests as the public's need for reassurance that their ingroup members, especially those who are particularly vulnerable to the threat, will be taken care of.

In a similar vein, the willingness to support stiffer penalties and law enforcement for the sake of safety from the disease, as seen in Theme 2, is consistent with research that people from high power distance societies tend to respect and accept what the authorities propose is best for the country (Schermerhorn \& Bond, 1997). Individuals are expected to act according to social norms in collectivistic cultures. During a pandemic, these norms include preventive health behaviors such as maintaining good personal hygiene, physical distancing, and wearing a mask in public. In tight societies like Singapore, there is a low tolerance for deviating from these norms and not adhering to proposed measures for the collective good of society. Hence, this translates to individuals wanting and being more accepting of stringent precautionary measures, government surveillance, and more serious punishments for deviance (Gelfand et al., 2011; Guan et al., 2020).

\section{Implications}

We found that HBM proved to be a valuable tool for identifying perceived susceptibility as one of the public's concerns during a pandemic. According to HBM, people are more likely to perform health-seeking actions to address the threat when they perceive a health risk and have self-efficacy to perform these actions.

Before they assess whether to act or not, the public needs to gather information related to the threat, which is the COVID-19 pandemic in this context. Hence, to aid the public in making sense of the COVID-19 situation, authorities need to provide information related to the components in the HBM: the likelihood of contracting COVID-19, the severity of contracting COVID-19, the effectiveness of the measures that are used to tackle COVID-19 transmissions, and assurance that they would be able to perform the proposed measures to minimize the spread of COVID-19. 
Analyzing the information shared on social media platforms can be helpful to local authorities for assessing and addressing the public's concerns. Existing work has demonstrated the value of social media in communicating crisis information to the public during a pandemic (Chua, 2020; Kaila \& Prasad, 2020).

The possibility of combining HBM and cultural factors such as collectivism can provide a more holistic picture of the public's concerns during a pandemic. More collectivistic societies such as Singapore are more likely to support actions to protect the collective interest. Individuals are expected to engage in health behaviors like mask-wearing or self-isolation for the collective good over any perceived benefits to themselves. For collectivistic societies, there is greater support for punitive actions against behaviors that undermine the collective good and for authorities to police such behavior. During times of crisis, the public has greater expectations of the authorities to be able to effectively manage the crisis. Given the role that collectivism plays in shaping public concerns, this highlights that in a pandemic response, it is important to consider the role of cultural factors in shaping the public's willingness to adopt a recommended health behavior.

\section{Limitations and Future Directions}

First, this study examined Facebook comments of Singapore media brands, which means that this study's findings may not be fully generalizable to other countries due to differences in cultural factors. More work can be done in terms of exploring cultural differences in risk communications during a health pandemic by comparing data from different countries.

As the working language for Singapore is English, the study was done using English-language posts and comments. However, Singapore has four official languages as well as media brands that serve news content in these languages. Future work can capture the comments of the public in these other media brands as it can provide a more comprehensive understanding of public concerns by segments of society who do not use English-language sources of news. 
Finally, the current study analyzed comments in response to government precautionary measures on social media in the first 6 months to infer the psychological concerns that the public may have by using a topic modelling approach. However, as the pandemic situation is still ongoing, there may be unforeseen situations that can appear, which would create new topics for analysis. More work can be done to explore how these topics emerge and change over time to better understand how these needs can shift over time.

\section{Conclusion}

The current study analyzed comments in response to government precautionary measures on social media to infer the psychological concerns that the public may have. A better understanding of these concerns can help authorities communicate risks more effectively, leading to more accurate risk perceptions and desirable behavioral responses during crises.

\section{ORCID}

Xingyu Ken Chen $\odot$ https://orcid.org/oooo-0003-3733-4015

Anais Ang ๑ https://orcid.org/oooo-0002-3774-6573

Jing Yi Lee $\odot$ https://orcid.org/oooo-00o2-1885-9871

Jason Wong $\odot$ https://orcid.org/oooo-0003-1226-9536

Neo Loo Seng ๑ https://orcid.org/oooo-0003-1956-6816

Gabriel Ong ๑ https://orcid.org/oooo-0003-3239-0480

Majeed Khader $\odot$ https://orcid.org/oooo-00o2-7928-2332 


\section{References}

Abdullah, Z., \& Salamat, H. (2020, January 23). Singapore confirms first case of Wuhan virus. CNA. https://web.archive. org/web/20200123141601/https://www.channelnewsasia. $\mathrm{com} / \mathrm{news} /$ singapore/wuhan-virus-pneumonia-singaporeconfirms-first-case-12312860

Abu Baker, J. (2020, June 2). Singapore's circuit breaker and beyond: Timeline of the COVID-19 reality. CNA. https:// web.archive.org/web/20200603072848/https://www. channelnewsasia.com/news/singapore/covid-19-circuitbreaker-chronicles-charting-evolution-12779048

Aravindan, J. G., Aradhana. (2020, September 18). Why is Singapore's COVID-19 death rate the world's lowest. Reuters. https://web.archive.org/web/20200923003219/https://www. reuters.com/article/health-coronavirus-singapore-explaineridUSKBN2680TF

Carico, R. "Ron," Sheppard, J., \& Thomas, C. B. (2020). Community pharmacists and communication in the time of COVID-19: Applying the health belief model. Research in Social and Administrative Pharmacy. https://doi.org/10.1016/j. sapharm.2020.03.017

Chua. (2020, January 31). Going Viral: How Singaporeans Reacted On FB As Wuhan Coronavirus Outbreak Worsened. Analytix Labs. https://web.archive.org/web/20210412152308/https:// www.analytix-labs.com/insights/wuhan

Elgzar, W. T., Al-Qahtani, A. M., Elfeki, N. K., \& Ibrahim, H. A. (2020). COVID-19 outbreak: Effect of an educational intervention based on health belief model on nursing students' awareness and health beliefs at Najran University, Kingdom of Saudi Arabia. African Journal of Reproductive Health, 24(2), 78-86.

Gallagher, R. J., Reing, K., Kale, D., \& Ver Steeg, G. (2017). Anchored correlation explanation: Topic modeling with minimal domain knowledge. Transactions of the Association for Computational Linguistics, 5, 529-542. https://doi.org/10.1162/ tacl_a_00078 
Gelfand, M. J., Raver, J. L., Nishii, L., Leslie, L. M., Lun, J., Lim, B. C., Duan, L., Almaliach, A., Ang, S., Arnadottir, J., Aycan, Z., Boehnke, K., Boski, P., Cabecinhas, R., Chan, D., Chhokar, J., D’Amato, A., Ferrer, M., Fischlmayr, I. C., ... Yamaguchi, S. (2011). Differences Between Tight and Loose Cultures: A 33-Nation Study. Science, 332(6033), 1100-1104. https://doi.org/10.1126/science.1197754

Germani, A., Buratta, L., Delvecchio, E., \& Mazzeschi, C. (2020). Emerging Adults and COVID-19: The role of individualismcollectivism on perceived risks and psychological maladjustment. International Journal of Environmental Research and Public Health, 17(10), 3497. https://doi.org/10.3390/ ijerph17103497

Gov.sg. (2020). Gov.sg launches new channels to keep the public informed about COVID-19. https://web.archive.org/ web/20200403183322/https://www.mci.gov.sg/pressroom/ news-and-stories/pressroom/2020/4/gov-sg-launches-newchannels-to-keep-the-public-informed-about-covid-19

Guan, Y., Deng, H., \& Zhou, X. (2020). Understanding the impact of the COVID-19 pandemic on career development: Insights from cultural psychology. Journal of Vocational Behavior, 119, 103438. https://doi.org/10.1016/j.jvb.2020.103438

Ho, C. S., Chee, C. Y., \& Ho, R. C. (2020). Mental health strategies to combat the psychological impact of COVID-19 beyond paranoia and panic. Ann Acad Med Singapore, 49(1), 1-3. https://doi.org/10.47102/annals-acadmedsg.202043

Hofstede, G. (2001). Culture's consequences: Comparing values, behaviors, institutions and organizations across nations. Sage Publications.

Huang, F., Ding, H., Liu, Z., Wu, P., Zhu, M., Li, A., \& Zhu, T. (2020). How fear and collectivism influence public's preventive intention towards COVID-19 infection: A study based on big data from the social media. BMC Public Health, 20(1), 1707. https://doi.org/10.1186/s12889-020-09674-6

Huynh, T. L. D. (2020). Does culture matter social distancing under the COVID-19 pandemic? Safety Science, 130, 104872. https://doi.org/10.1016/j.ssci.2020.104872 
Ibuka, Y., Chapman, G. B., Meyers, L. A., Li, M., \& Galvani, A. P. (2010). The dynamics of risk perceptions and precautionary behavior in response to $2009\left(\mathrm{H}_{1} \mathrm{~N}_{1}\right)$ pandemic influenza. $B M C$ Infectious Diseases, 1o(1), 296. https://doi.org/10.1186/14712334-10-296

Jang, K., \& Baek, Y. M. (2019). When information from public health officials is untrustworthy: The use of online news, interpersonal networks, and social media during the MERS outbreak in South Korea. Health Communication, 34(9), 991-998. Jiang, S., Wei, Q., \& Zhang, L. (2020). Impacts of cultural difference on the transmission of COVID-19 individualism vs. collectivism (SSRN Scholarly Paper ID 3646229). https://doi.org/10.2139/ ssrn.3646229

John, D. L., Kim, E., Kotian, K., Ong, K. Y., White, T., Gloukhova, L., Woodbridge, D. M., \& Ross, N. (2019). Topic modeling to extract information from nutraceutical product reviews. 2019 16th IEEE Annual Consumer Communications Networking Conference (CCNC), 1-6. https:/doi.org/10.1109/ CCNC.2019.8651723

Jose, R., Narendran, M., Bindu, A., Beevi, N. L. M., \& Benny, P . V. (2020). Public perception and preparedness for the pandemic COVID 19: A Health Belief Model approach. Clinical Epidemiology and Global Health. https://doi.org/10.1016/j. cegh.2020.06.009

Kaila, R. P., \& Prasad, A. V. (2020). Informational flow on Twitter-Corona virus outbreak-Topic modelling approach. International Journal of Advanced Research in Engineering and Technology (IJARET), 11(3).

Kasdan, D. O., \& Campbell, J. W. (2020). Dataveillant Collectivism and the Coronavirus in Korea: Values, Biases, and SocioCultural Foundations of Containment Efforts. Administrative Theory \& Praxis, 42(4), 604-613. https://doi.org/10.1080/108 41806.2020 .1805272

Kim, H. S., Sherman, D. K., \& Updegraff, J. A. (2016). Fear of Ebola: The Influence of Collectivism on Xenophobic Threat Responses. Psychological Science, 27(7), 935-944. https://doi. org/10.1177/0956797616642596 
Koh, F. (2020). Media showcases role in helping to tackle Covid-19 crisis. The Straits Times. https://web.archive. org/web/20201001030804/https://www.straitstimes.com/ singapore/media-showcases-role-in-helping-to-tackle-covid19-crisis

Leong, D. (2020). Commentary: Telegram, the powerful COVID19 choice of communications by many governments. CNA. https://web.archive.org/web/20200516024440/https://www. channelnewsasia.com/news/commentary/coronaviruscovid-19-government-telegram-whatsapp-fake-newsinfo- 12707902

Li, D., Chaudhary, H., \& Zhang, Z. (2020). Modeling spatiotemporal pattern of depressive symptoms caused by COVID19 using social media data mining. International Journal of Environmental Research and Public Health, 17(14), 4988. https://doi.org/10.3390/ijerph17144988

Ministry of Health. (2020). Circuit Breaker To Minimise Further Spread Of Covid-19. https://web.archive.org/ web/20200403092407/https://www.moh.gov.sg/newshighlights/details/circuit-breaker-to-minimise-furtherspread-of-covid-19

Ng, J. Y. Y., Ntoumanis, N., Thøgersen-Ntoumani, C., Deci, E. L., Ryan, R. M., Duda, J. L., \& Williams, G. C. (2012). SelfDetermination theory applied to health contexts: A MetaAnalysis. Perspectives on Psychological Science, 7(4), 325-340. https://doi.org/10.1177/1745691612447309

Nurhayati-Wolff, H. (2021). Number of COVID-19 infections in SingaporeasofFebruary1, 2021.Statista.https://web.archive.org/ web/20210210154953/https:/www.statista.com/statistics/ 1098985/singapore-covid-19-total-cases/

Porat, T., Nyrup, R., Calvo, R. A., Paudyal, P., \& Ford, E. (2020). Public health and risk communication during COVID19-Enhancing psychological needs to promote sustainable behavior change. Frontiers in Public Health, 8. https://doi. org/10.3389/fpubh.2020.573397 
Rekhi, S. (2020, April 15). Coronavirus: Survey shows people rely on trustworthy news organisations for information. The Straits Times. https://web.archive.org/web/20200417060939/ https://www.straitstimes.com/world/coronavirus-surveyshows-people-rely-on-trustworthy-news-organisationsfor-information

Rosenstock, I. M., Strecher, V. J., \& Becker, M. H. (1988). Social learning theory and the health belief model. Health Education Quarterly, 15(2), 175-183. https://doi. org/10.1177/109019818801500203

Ryan, R. M., Patrick, H., Deci, E. L., \& Williams, G. C. (2008). Facilitating health behaviour change and its maintenance: Interventions based on self-determination theory. The European Health Psychologist, 10(1), 2-5.

Schermerhorn, J. R., \& Bond, M. H. (1997). Cross-cultural leadership dynamics in collectivism and high power distance settings. Leadership \& Organization Development Journal, 18(4), 187-193.

Statista. (2020a). Penetration rate of top social networks in Singapore as of the 3 rd quarter of 2019. https://web.archive. org/web/20200614011201/https://www.statista.com/ statistics/284466/singapore-social-network-penetration/

Statista. (2020b). Share of respondents who consume news through online media in Singapore as of February 2020, by media brand. https://web.archive.org/web/20210412153758/https://www. statista.com/statistics/982736/singapore-weekly-use-onlinenews-media-by-brands/

Triandis, H. C. (2001). Individualism-Collectivism and Personality. Journal of Personality, 69(6), 907-924. https://doi. org/10.1111/1467-6494.696169

Turrell, C. (2021, February 1). I'm a doctor in Singapore. Our COVID-19 cases have been low since last fall-Here's what we're doing right. Business Insider. https://web.archive.org/ web/20210201135250/https://www.businessinsider.com/ doctor-in-singapore-covid-19-cases-are-low-heres-why2021-1? $\mathrm{r}=\mathrm{DE} \& \mathrm{IR}=\mathrm{T}$ 
Vaughan, E., \& Tinker, T. (2009). Effective health risk communication about pandemic influenza for vulnerable populations. American Journal of Public Health, 99(S2), S324-S332. https:// doi.org/10.2105/AJPH.2009.162537

Ver Steeg, G., \& Galstyan, A. (2014). Discovering Structure in High-Dimensional Data Through Correlation Explanation. In Z. Ghahramani, M. Welling, C. Cortes, N. Lawrence, \& K. Q. Weinberger (Eds.), Advances in Neural Information Processing Systems (Vol. 27). Curran Associates, Inc. https://arxiv.org/ abs/1406.1222

Walrave, M., Waeterloos, C., \& Ponnet, K. (2020). Adoption of a Contact Tracing App for Containing COVID-19: A Health Belief Model Approach. JMIR Public Health and Surveillance, 6(3), e20572. https://doi.org/10.2196/20572

Willis, E., \& Painter, C. (2019). The Needle and the Damage Done: Framing the Heroin Epidemic in the Cincinnati Enquirer. Health Communication, 34(6), 661-671. https://doi.org/10.10 8o/10410236.2018.1431023 